\title{
The Pharmacokinetics of the CYP3A Substrate Midazolam in Morbidly Obese Patients Before and One Year After Bariatric Surgery
}

\author{
Margreke J. Brill ${ }^{1,2}$ - Anne van Rongen ${ }^{1,2}$ • Eric P. van Dongen ${ }^{3}$. Bert van Ramshorst ${ }^{4}$ - Eric J. Hazebroek ${ }^{4}$ - Adam S. Darwich ${ }^{5}$.
} Amin Rostami-Hodjegan ${ }^{5}$. Catherijne A. Knibbe ${ }^{1,2}$

Received: 3 April 2015 / Accepted: 6 July 2015 / Published online: 23 July 2015

(C) The Author(s) 2015

\section{ABSTRACT}

Purpose Bariatric surgery is nowadays commonly applied as treatment for morbid obesity $\left(\mathrm{BMI}>40 \mathrm{~kg} / \mathrm{m}^{2}\right)$. As information about the effects of this procedure on a drug's pharmacokinetics is limited, we aimed to evaluate the pharmacokinetics of CYP3A probe substrate midazolam after oral and intravenous administration in a cohort of morbidly obese patients that was studied before and 1 year post bariatric surgery.

Methods Twenty morbidly obese patients (aged 26-58 years) undergoing bariatric surgery participated in the study of which 18 patients returned 1 year after surgery. At both occasions, patients received $7.5 \mathrm{mg}$ oral and $5 \mathrm{mg}$ intravenous midazolam separated by $160 \pm 48 \mathrm{~min}$. Per patient and occasion, a mean of 22 blood samples were collected. Midazolam concentrations were analyzed using population pharmacokinetic modeling.

Results One year after bariatric surgery, systemic clearance of midazolam was higher $[0.65(7 \%)$ versus $0.39(11 \%) \mathrm{L} / \mathrm{min}$, mean $\pm \operatorname{RSE}(P<0.01)$, respectively] and mean oral transit time (MTT) was faster [23 (20\%) versus 51 (15\%) minutes $(P<0.01)]$, while oral bioavailability was unchanged $(0.54$ $(9 \%))$. Central and peripheral volumes of distribution were overall lower $(P<0.05)$.

Conclusions In this cohort study in morbidly obese patients, systemic clearance was 1.7 times higher 1 year after bariatric surgery, which may potentially result from an increase in hepatic CYP3A activity per unit of liver weight. Although MTT was found to be faster, oral bioavailability remained unchanged, which considering the increased systemic clearance implies an increase in the fraction escaping intestinal first pass metabolism.

KEY WORDS bariatric surgery · midazolam . pharmacokinetics . CYP3A

\section{ABBREVIATIONS}

MTT Mean oral transit time

NPDE Normalized prediction distribution errors

OFV Objective function value

RYGB Roux and - Y gastric bypass

\section{INTRODUCTION}

The prevalence of morbid obesity (body mass index, BMI $>40 \mathrm{~kg} / \mathrm{m}^{2}$ ) is increasing worldwide. In the United States, $6 \%$ of the population is morbidly obese while in Europe prevalence of obesity (BMI $>30 \mathrm{~kg} / \mathrm{m}^{2}$ ) ranges between 10 and

Electronic supplementary material The online version of this article (doi: | 0. I007/s | | 095-0 I 5- |752-9) contains supplementary material, which is available to authorized users.

\section{Catherijne A. Knibbe \\ c.knibbe@antoniusziekenhuis.nl}

Division of Pharmacology, Leiden Academic Centre for Drug Research, Leiden University, Leiden, The Netherlands

2 Department of Clinical Pharmacy, St. Antonius Hospital, Koekoekslaan I, 3435 CM Nieuwegein, The Netherlands
3 Department of Anaesthesiology and Intensive Care, St. Antonius Hospital, Nieuwegein, The Netherlands

4 Department of Surgery, St. Antonius Hospital, Nieuwegein, The Netherlands

5 Manchester Pharmacy School, University of Manchester, Manchester, Great Britain, UK 
$30 \%$ depending on the country $(1,2)$. Exact numbers on the prevalence of morbid obesity in Europe are lacking, but are estimated to range between 1 and $7 \%(3-5)$.

Bariatric surgery is considered the most effective treatment for morbid obesity $(6,7)$. In 2011, more than 340,000 bariatric surgeries, including Roux and - Y gastric bypass (RYGB) and sleeve gastrectomy, were performed worldwide (8). During a bariatric procedure, the stomach is reduced to a sleeve like structure or a small pouch and, in case of a roux and $-\mathrm{Y}$ gastric bypass, the duodenum and initial part of the small intestine are bypassed (9-11). These alterations in the gastrointestinal tract may cause an increase in stomach $\mathrm{pH}$, an increase in gastric emptying time, and a decrease in the surface area of absorption $(9,12,13)$.

As such, a bariatric procedure may impact a drug's pharmacokinetics and have consequences for dosing. In particular for drugs undergoing CYP3A metabolism, it seems relevant to study the impact of bariatric surgery, as the CYP3A enzyme resides not only in the liver but also in the gut wall and is an important drug metabolising enzyme involved in the metabolism of approximately $25 \%$ of all clinically used drugs (14). Besides bariatric surgery induced anatomical changes to the gastro-intestinal tract, the resulting reduction in (over)weight may also influence CYP3A activity itself (15). It is well known that obese patients suffer from low-grade inflammation caused by macrophages and adipocytes in the adipose tissue which excrete inflammation markers and adipokines, including Il-6 and TNF-alpha (16-18) which may lead to reduced CYP3A activity $(15,19,20)$. As studies in morbidly obese patients before and after bariatric surgery show a reduction in inflammation status in patients after bariatric surgery, it is hypothesized that CYP3A activity in patients after bariatric surgery recovers $(21,22)$. However, it seems that the inflammation status does not completely change back to non-obese (never been obese) individuals, as 6 months post surgery values of leptin, adiponectin and $\mathrm{C}$-reactive protein (CRP) did not return to values found for lean (never been obese) patients (21).

Midazolam is considered a model substrate drug for CYP3A activity as it is primarily metabolized by CYP3A (23). Therefore, in this study we aimed to evaluate the pharmacokinetics of midazolam after oral and intravenous administration in a cohort of morbidly obese patients that was studied before and 1 year post bariatric surgery. The results are used to evaluate consequences for dosing of midazolam in patients after bariatric surgery.

\section{MATERIALS AND METHODS}

\section{Study Design and Patients}

This is a prospective observational and interventional study in morbidly obese adult patients (NTC01519726, EudraCT
2011-003293-93). Before participation, all patients gave written informed consent. The study was approved by the local human research and ethics committee (VGMO, NL35861.100.11) and was conducted according to the principles of the Declaration of Helsinki (version 22-10-2008) and in accordance with the Medical Research Involving Human Subjects Act (WMO) of the Netherlands.

Morbidly obese patients undergoing a laparoscopic gastric bypass or sleeve surgery between 18 and 65 years were eligible for inclusion in the study. Patients were excluded if they used CYP3A inducing or inhibiting medication (24), used products containing grapefruit, wild grape, banpeiyu, pomegranate, star fruit or black berry within 2 weeks before the study, were pregnant, were breastfeeding, were younger than 18 or older than 60 years or suffered from renal insufficiency (eGFR MDRD4<60 $\mathrm{mL} / \mathrm{min}$ ).

\section{Study Procedures}

The study consisted of two occasions. The first occasion was on the day of laparoscopic bariatric surgery (occasion 1), of which the details and results have been described in a previous report (25). One year after bariatric surgery, the 20 patients who participated on occasion 1 , were invited to participate in the second part of the study (occasion 2). The period of 1 year was chosen based on the Swedish Obese Subjects study showing a mean weight loss optimum of $32 \%$ of body weight $0.5-$ 2 years after bariatric surgery (26).

For both occasions, patients fasted from midnight until the study started in the morning (typically at 09:00 o'clock) and were not allowed to eat or drink until $1 \mathrm{~h}$ post intravenous midazolam dose. At first a $7.5 \mathrm{mg}$ midazolam tablet was administered orally and after $160 \pm 48 \mathrm{~min}$ an i.v. dose of $5 \mathrm{mg}$ was administered. For the first occasion, the i.v. dose coincided with the induction of anesthesia for the bariatric surgical procedure while for the second occasion the i.v. dose was administered at $150 \mathrm{~min}$ after oral dose. Blood samples were collected at 5, 15, 30, 45, 55, 65, 75, 90, 120, 150 after oral dose and at 5, 15, 30, 60, 90, 120, 150, 180, 240 and 300, 390 and $510 \mathrm{~min}$ after intravenous dose at occasion 1 , and at 5, 15, 30, 60, 90, 120, 150, 180, 240 and $300 \mathrm{~min}$ after intravenous dose at occasion 2. After collection, blood samples were centrifuged and plasma was stored at $-80^{\circ} \mathrm{C}$ until analysis. Samples were analyzed as described before (25). The Richmond Agitation Sedation Scale (RASS) was used to score the level of sedation in each participant after midazolam oral dose until administration of the intravenous dose (27).

\section{Population Pharmacokinetic Analysis and Internal Validation}

The population pharmacokinetic analyses was performed by means of nonlinear mixed effects modelling using NONMEM 
(version 7.2) (28). Pirana (2.7.1) and R (2.15) were used to visualize the data. Discrimination between different structural and statistical models was made by comparison of the objective function value (OFV, i.e., $-2 \log$ likelihood [-2LL]). A pvalue below 0.05 , representing a decrease of 3.84 in the $\mathrm{OFV}$, was considered statistically significant. In addition, goodnessof-fit plots (observed versus individual-predicted concentrations, observed versus population-predicted concentrations, conditional weighted residuals versus time and versus population-predicted concentrations plots) were used for diagnostic purposes. Furthermore, the confidence interval of the parameter estimates, the correlation matrix and visual improvement of the individual plots were used to evaluate the model. The internal validity of the population pharmacokinetic model was assessed by the bootstrap re-sampling method using 500 replicates and normalized prediction distribution errors (NPDE) (29). Parameters obtained with the bootstrap replicates were compared with the estimates obtained from the original dataset and NPDE plots were checked for normal distribution characteristics and trends in the errors.

Midazolam concentration-time profiles were analysed separately (occasion 1, occasion 2) and simultaneously (occasion 1 and 2). The separate pharmacokinetic analyses allowed for initial exploration of the data and evaluation of covariate relationships within each population. For all analyses, two- and three compartment pharmacokinetics models were tested. For the description of the oral absorption phase, different models were tested including first order absorption, zero order absorption and a transit compartment model in which transit compartment rates (Ktr) were equalized to the absorption rate constant (Ka) (30). The mean oral transit time (MTT), which represents the average time for the drug from oral dose administration to appearance at the sample site, can be calculated from Ktr using MTT $=(\mathrm{N}+$ 1)/Ktr in which $\mathrm{N}$ is the number of transit compartments. For the statistical model, the individual parameter estimate (Empirical Bayes Estimate or post hoc value) of the ith individual was modelled according to (Eq. 1):

$\theta_{i}=\theta_{\text {mean }} \times \exp \left(\eta_{i}\right)$

where $\theta_{\text {mean }}$ is the population mean parameter value, and $\eta_{i}$ is a random variable for the ith individual with a mean of zero and variance of $\omega^{2}$, assuming log-normal distribution in the population. The residual variability, resulting from assay errors, model misspecifications and other unexplained sources, was best described with a proportional error model. The jth observed midazolam concentration of the ith patient $\left(\mathrm{Y}_{\mathrm{ij}}\right)$ in Eq. 2:

$\Upsilon_{i j}=C_{\text {pred }, i j} \times\left(\mid+\varepsilon_{i j}\right)$

where $\mathrm{C}_{\text {pred,ij }}$ is the population predicted midazolam concentration of the ith individual at the $\mathrm{jth}$ time, and $\varepsilon_{\mathrm{ij}}$ is a random variable with a mean of zero and variance of $\sigma^{2}$.

\section{Covariate Analysis}

Covariates were plotted independently against the individual estimates of pharmacokinetic parameters to visualize potential relations. The following covariates were tested: body weight, BMI, lean body weight (31), age, sex and bariatric surgery. The influence of the binary covariates bariatric surgery and sex was explored by means of estimating two separate thetas or by a factor (' $Z$ ') of increase/decrease according to Eq. 3:

$P_{i}=P_{p} \times z^{\text {COVARIATE }}$

where $\mathrm{P}_{\mathrm{i}}$ and $\mathrm{P}_{\mathrm{p}}$ represent the individual and population parameter estimate, $Z$ represents the factor for increase or decrease for the patients subgroup with a $Z$ of 1 in case the covariate equals 0 or a $\mathrm{Z}$ of $\mathrm{Z}$ in case the covariate equals 1 . In case the binary covariate bariatric surgery for a specific parameter improved the model significantly, it was evaluated whether this factor of increase or decrease could be related to the difference in body weight, lean body weight (31) or BMI between occasion 1 and 2 using the following equations:

If Occasion $=1: P_{i}=P_{p}$

If Occasion $=2: P_{i}=P_{p} \times$ factor $\cdot\left(C O V_{\text {Beforesurgery }}-C O V_{\text {AfferSurgery }}\right)$

Furthermore, it was tested whether body weight, lean body weight, age or BMI was a linear (Eq. 7) or nonlinear (Eq. 8) covariate within occasion 1 or 2 using the following equations:

If Occasion $=1: P_{i}=P_{p}$

If Occasion $=2: P_{i}=P_{p} \times\left(I+W \times\left(C O V-C O V_{\text {median }}\right)\right.$

And/or:

If Occasion $=2: P_{i}=P_{p} \times\left(\frac{C O V}{C O V_{\text {median }}}\right)^{X}$

where $\mathrm{P}_{\mathrm{i}}$ and $\mathrm{P}_{\mathrm{p}}$ represent individual and population parameter estimates, respectively; $\mathrm{COV}$ represents the covariate; $\mathrm{COV}_{\text {median }}$ represents the median covariate value; $\mathrm{X}$ represents the exponential scaling factor; and $\mathrm{W}$ represents the correlation factor between the population pharmacokinetic parameters and the covariate. The occasion conditions were switched vice versa to test covariate relationships within both groups.

Continuous covariates for both occasion 1 and 2 simultaneously were tested using linear and non-linear equations (Eqs. 9 and 10).

$P_{i}=P_{p} \times\left(\frac{C O V}{C O V_{\text {median }}}\right)^{X}$

$P_{i}=P_{p} \times\left(I+W \times\left(C O V-C O V_{\text {median }}\right)\right.$

Potential covariates were separately entered into the model and statistically tested by use of the OFV and, if applicable, 
the $95 \%$ CI of the additional parameter. In addition, if applicable, it was evaluated whether the interindividual variability in the parameter concerned reduced in value upon inclusion of the covariate on the parameter. After forward inclusion $(p<0.05)$, a backward exclusion procedure was applied to justify the inclusion of a covariate $(p<0.001)$. The choice of the covariate model was further evaluated as discussed above (see Population pharmacokinetic analysis and internal validation section).

\section{Model Simulations}

The final population pharmacokinetic model was used to simulate the midazolam concentration time curves after a $7.5 \mathrm{mg}$ oral dose, a $5 \mathrm{mg}$ intravenous dose and a $2.5 \mathrm{mg} / \mathrm{h}$ continuous infusion. Using Monte Carlo simulations, 1000 individuals were randomly generated based on body weight distribution of our study $(144 \pm 26 \mathrm{~kg})$ and simulations based on theta and eta values of the final PK model were performed using NONMEM.

\section{RESULTS}

\section{Patients and Data}

Of the 20 morbidly obese patients who participated in the first part of the trial (occasion 1), 18 patients returned $52 \pm 3$ weeks after bariatric surgery (occasion 2) and lost a mean of $44.5 \pm$ $10.2 \mathrm{~kg}$ of body weight. Two of the 20 patients were lost to follow up to participate at occasion 2. Patients and study characteristics are summarized in Table I. Figure 1 shows the midazolam concentration time values measured at both study occasions. At occasion 1, the occurrence of the peak concentrations after the i.v. dose were found to vary largely, which resulted from differences in time of administration of the intravenous midazolam. For post-bariatric surgery patients, the

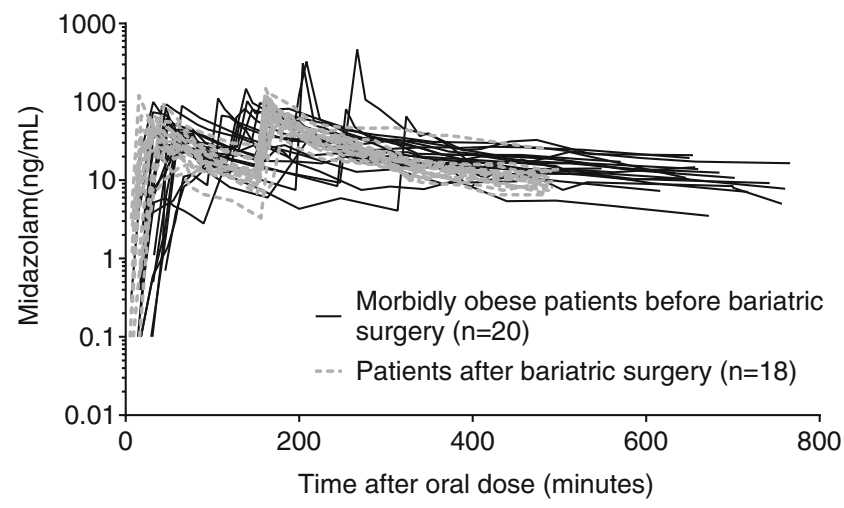

Fig. I Midazolam concentration versus time after oral dose profiles upon a $7.5 \mathrm{mg}$ oral midazolam dose and a $5 \mathrm{mg}$ intravenous dose separated by 160 \pm 48 min in 20 morbidly obese patients before (black lines) and I year after surgery (grey dotted lines). Two patients were unable to participate I year after surgery.

concentration time curves show a slightly earlier maximum concentration $\left(\mathrm{C}_{\max }\right)$ after oral dose in comparison to morbidly obese patients before bariatric surgery, while in a few individuals of the morbidly obese patient group peak concentrations after the intravenous dose seemed higher.

\section{Pharmacokinetic Analysis}

For the population pharmacokinetic analysis including the data of both occasions a three compartment model, in which the second peripheral volume was a fraction of the first peripheral compartment best described the data. Midazolam oral absorption was best described using five transit compartments, while the addition of more transit compartments did not further improve the fit of midazolam concentrations after both oral and intravenous administration. Table II shows the parameters estimates of the simple pharmacokinetic model without covariates.

In the covariate analysis, the binary covariate 'bariatric surgery' proved an important covariate for clearance (CL),

Table I Patients and Study Characteristics (Mean \pm Standard Deviation)

\begin{tabular}{|c|c|c|c|c|}
\hline & $\begin{array}{l}\text { Morbidly obese patients } \\
\text { before surgery }(n=20)\end{array}$ & $\begin{array}{l}\text { Minimum- } \\
\text { maximum }\end{array}$ & $\begin{array}{l}\text { Patients after bariatric } \\
\text { surgery }(n=18 \text { of } 20)\end{array}$ & $\begin{array}{l}\text { Minimum- } \\
\text { maximum }\end{array}$ \\
\hline Female/Male & $12 / 8$ & & $1 \mid / 7$ & \\
\hline Age (years) & $43.6 \pm 7.6$ & $26-57$ & $45.5 \pm 7.4$ & $27-58$ \\
\hline Body weight (kg) & $144.4 \pm 21.7$ & $112-186$ & $98.3 \pm 18.0$ & $62-138$ \\
\hline $\mathrm{LBW}(\mathrm{kg})$ & $71.5 \pm 11.9$ & $53-95$ & $59.5 \pm 10.0$ & 39-73 \\
\hline $\mathrm{BMI}\left(\mathrm{kg} / \mathrm{m}^{2}\right)$ & $47.1 \pm 6.5$ & $40-68$ & $31.9 \pm 5.9$ & $24-50$ \\
\hline Weight loss (kg) & - & - & $44.5 \pm 10.2$ & $21-58$ \\
\hline Number of midazolam samples per patient & $22 \pm 3$ & $13-24$ & $21 \pm 1$ & 19-22 \\
\hline Gastric bypass/ sleeve gastrectomy & - & - & $16 / 2$ & - \\
\hline Time post surgery (weeks) & - & - & $51.8 \pm 2.5$ & $49-57$ \\
\hline
\end{tabular}

$B M /$ body mass index, LBW lean body weight 
Table II Parameter Values of the Simple (Without Covariates) and Final (With Covariates) Population Pharmacokinetic Models and Results of the Bootstrap Analysis

\begin{tabular}{|c|c|c|c|}
\hline Parameter & $\begin{array}{l}\text { Simple model of simultaneous } \\
\text { analysis } \\
\text { Value (RSE) }\end{array}$ & $\begin{array}{l}\text { Final model of simultaneous } \\
\text { analysis } \\
\text { Value (RSE) }\end{array}$ & $\begin{array}{l}\text { Bootstrap of final simultaneous } \\
\text { model } \\
\text { Median (2.5-97.5 percentile) }\end{array}$ \\
\hline \multicolumn{4}{|l|}{ Fixed effects } \\
\hline $\mathrm{Ka}=\mathrm{Ktr}$ & $0.199(11 \%)$ & - & - \\
\hline $\mathrm{Ka}=\mathrm{Ktr}_{\text {Morbidly obese }}\left(\mathrm{min}^{-1}\right)$ & - & $0.117(15 \%)$ & $0.114(0.08-0.15)$ \\
\hline $\mathrm{Ka}=\mathrm{Ktr}_{\text {Bariatric patients }}\left(\min ^{-1}\right)$ & - & $0.267(19 \%)$ & $0.263(0.08-0.45)$ \\
\hline $\mathrm{F}$ & $0.560(10 \%)$ & $0.537(9 \%)$ & $0.543(0.44-0.63)$ \\
\hline $\mathrm{CL}(\mathrm{L} / \mathrm{min})$ & $0.381(26 \%)$ & - & - \\
\hline $\mathrm{CL}_{\text {Morbidly obese }}(\mathrm{L} / \mathrm{min})$ & - & $0.385(11 \%)$ & $0.366(0.29-0.48)$ \\
\hline $\mathrm{fCL}_{\text {Bariatric patients }}(\mathrm{L} / \mathrm{min})$ & - & $1.68(7 \%)\left(* C L_{\text {morbidly obese }}=0.647\right)$ & I.70 (I.18-2.18) $\left(* C L_{\text {morbidly obese }}=0.634\right)$ \\
\hline$Q(L / m i n)$ & $0.888(21 \%)$ & - & - \\
\hline QMorbidly obese $(\mathrm{L} / \mathrm{min})$ & - & $0.669(24 \%)$ & $0.764(0.11-1.23)$ \\
\hline $\mathrm{fQ}_{\text {Bariatric patients }}(\mathrm{L} / \mathrm{min})$ & - & $3.22(32 \%)\left(* Q_{\text {Morbidly obese }}=2.15\right)$ & $2.907(-22.6-29.0)\left(* Q_{\text {Morbidly obese }}=3.7 I\right)$ \\
\hline Q2 & $0.644(21 \%)$ & $0.551(23 \%)$ & $0.548(0.25-0.86)$ \\
\hline $\mathrm{V}_{\text {central }}(\mathrm{L})$ & $54.7(17 \%)$ & - & - \\
\hline \multicolumn{4}{|c|}{$\mathrm{V}_{\text {central Morbidly obese }}=\mathrm{V}_{\text {median } \mathrm{BW}} *\left(\mathrm{I}+\mathrm{X}^{*}(\mathrm{BW}\right.$-median BW $\left.)\right)$} \\
\hline$V_{\text {median } B W}$ & - & $37.3(18 \%)$ & $37.2(17.8-56.8)$ \\
\hline$x$ & - & $0.0435(92 \%)$ & $0.052(-0.42-0.51)$ \\
\hline $\mathrm{V}_{\text {central Bariatric patients }}(\mathrm{L})$ & - & $37.3(18 \%)$ & 37.20 \\
\hline$V_{\text {Ist peripheral }}(L)$ & $247(30 \%)$ & - & - \\
\hline \multicolumn{4}{|c|}{$V_{\text {Peripheral Morbidly obese }}=V_{\text {median }} \mathrm{BW}^{*}(\mathrm{BW} / \text { median } \mathrm{BW})^{\mathrm{Y}}$} \\
\hline$V_{\text {median BW }}$ & - & $106(17 \%)$ & I I3 (20.9-190.3) \\
\hline Y & - & $3.93(20 \%)$ & $3.99(1.9-5.9)$ \\
\hline$V_{\text {Ist peripheral Bariatric patients }}(L)$ & - & $106(17 \%)$ & $113(1.9-5.9)$ \\
\hline $\mathrm{fV}_{2 \text { nd peripheral }}$ & $0.169(25 \%)\left(* V_{\text {Ist peripheral }}=42 \mathrm{~L}\right)$ & $0.359(27 \%)\left(V_{\text {Ist peripheral }}=38 \mathrm{~L}\right)$ & 0.31 I $(0.13-0.58)\left(* V_{\text {Ist peripheral }}=40 \mathrm{~L}\right)$ \\
\hline \multicolumn{4}{|l|}{ Interindividual variability (\%) } \\
\hline $\mathrm{K} \operatorname{tr}=\mathrm{Ka}$ & $50(17 \%)$ & $42.4(15 \%)$ & $40.6(27-54)$ \\
\hline$C L$ & $41.5(24 \%)$ & $19.7(38 \%)$ & $17.7(-14-32)$ \\
\hline $\mathrm{F}$ & $28.6(23 \%)$ & $33.4(18 \%)$ & $32.6(16-45)$ \\
\hline$V_{\text {central }}$ & $60.8(20 \%)$ & $53.7(39 \%)$ & $54.3(-49-102)$ \\
\hline$V_{\text {Ist peripheral }}$ & O FIX & O FIX & O FIX \\
\hline \multicolumn{4}{|l|}{ Proportional residual error (\%) } \\
\hline & $46.2(6 \%)$ & $42.1(5 \%)$ & $41.0(12.2)$ \\
\hline OFV & 6218 & 5885 & $5997(804)$ \\
\hline
\end{tabular}

$B W$ body weight (median = $127 \mathrm{~kg}$ for all data), $C L$ Clearance $(L / m i n), F$ Oral bioavailability, $f C L_{\text {Bariatric patients }}(L / m i n)$ fraction of midazolam clearance of morbidly obese patients to estimate bariatic patient clearance, $f_{\text {Bariatric patients }}$ fraction of intercompartmental clearance of morbidly obese patients to estimate intercompartmental clearance of bariatric patients, $f V_{\text {peripheral }}$ fraction of first peripheral volume of distribution to estimate second peripheral volume, Ktr transit compartment rate $\left(\mathrm{min}^{-1}\right)$, Ka oral absorption rate $\left(\mathrm{min}^{-1}\right)$, OFV Objective function value (-2LL), $\mathrm{Q}$ intercompartmental clearance (L/min), RSE(\%) relative standard error, $\vee$ Volume of distribution (L), $V_{\text {Peripheral }}$ first peripheral volume of distribution

oral absorption rate $(\mathrm{Ka})$, inter compartmental clearance $(\mathrm{Q})$ and volumes of distribution $(\mathrm{V})$. For clearance, the covariate bariatric surgery gave the largest drop in OFV $(-91 \Delta \mathrm{OFV}$, $p<0.001$, while a linear covariate relation with body weight resulted in a drop in OFV $(-80 \Delta \mathrm{OFV})$. After bariatric surgery, clearance was 1.68 times higher than in morbidly obese patients before surgery, while the extent of this increase could not be related to the loss in (lean) body weight $(p>0.05$,
Table II). Bariatric surgery as covariate on $\mathrm{Ka}$ also resulted in an improved fit of the model $(-167 \Delta \mathrm{OFV}, p<0.001)$. In the final model, Ka was separately estimated for both occasions and was found to have a larger value in patients after bariatric surgery $\left(0.117\right.$ versus $0.267 \mathrm{~min}^{-1}$, Table II). As a consequence, the mean oral transit time (MTT), which is calculated from the oral absorption rate, was $51.3(15 \%)$ before versus $22.6(19 \%)$ minutes after bariatric surgery. Furthermore, 
bariatric surgery resulted in a 3.22 times increase in inter compartmental clearance, Q $(0.669$ to $2.15 \mathrm{~L} / \mathrm{min},-16 \Delta \mathrm{OFV}$, $p<0.001)$. Finally, central and the peripheral volumes of distribution were overall lower in patients after bariatric surgery without a significant influence of (lean) bodyweight within this group. In the morbidly obese patients group, central and peripheral volume increased with body weight $(-6 \Delta \mathrm{OFV}$, $p<0.02$ and $-68 \Delta \mathrm{OFV}, p<0.001$, respectively, Table II). As the second peripheral volume of distribution was modeled as a fraction of the first peripheral volume of distribution, for morbidly obese patients before surgery it varied with body weight in a similar manner as the first peripheral volume of distribution (Table II). Concerning oral bioavailability (F) and intercompartmental clearance to the second peripheral compartment (Q2) none of the covariates were of significant influence $(p>0.05)$. Parameters estimates of the final pharmacokinetic model are shown in Table II and goodness of fit plots are shown in Fig. 2. A 500 replicate bootstrap showed validity of the model (94\% successful, Table II) and NPDE plots are presented in electronic supplementary material and showed a normal distribution of errors without any trends for both occasions.

In Fig. 3 the population mean and 90\% confidence interval of 1000 Monte Carlo midazolam dose simulations for morbidly obese patients before and after surgery are presented. After a $5 \mathrm{mg}$ intravenous dose, midazolam concentrations in a bariatric surgery patient show a higher initial midazolam concentration and a faster decline over time compared to a morbidly obese patient before surgery (Fig. 3a). Upon a midazolam $2.5 \mathrm{mg} / \mathrm{h}$ continuous infusion a bariatric patient is exposed to a lower steady state concentration in comparison to a morbidly obese patient (Fig. 3b), while steady state concentrations are reached approximately 2.5 times faster in bariatric patients $(\sim 14 \mathrm{~h})$ than in morbidly obese patient $(\sim 37 \mathrm{~h})$. Finally, oral midazolam in a bariatric patient will result in a shorter time to maximum concentration $\left(\mathrm{T}_{\max }, 32\right.$ versus $65 \mathrm{~min}$ ) and 1.5 times increase in midazolam $\mathrm{C}_{\max }$ in comparison to before surgery (Fig. 3c).

\section{DISCUSSION}

In this cohort study in which morbidly obese patients are studied until 1 year after bariatric surgery, we aimed to determine how and to what extent midazolam pharmacokinetics after oral and intravenous administration are affected by bariatric surgery. One year post bariatric surgery, we found that
Fig. 2 Observed versus individual predicted midazolam concentrations $(\mathbf{a})$, observed versus population predicted midazolam concentrations (b), conditional weighted residuals (CWRES) versus time (c) and population predicted midazolam concentrations (d) of the final model for 20 morbidly obese patients (black dots, occasion I) of which 18 returned I year post surgery for a second study visit (grey dots, occasion 2). The dashed line represents the line of identity $(x=$ y).
A

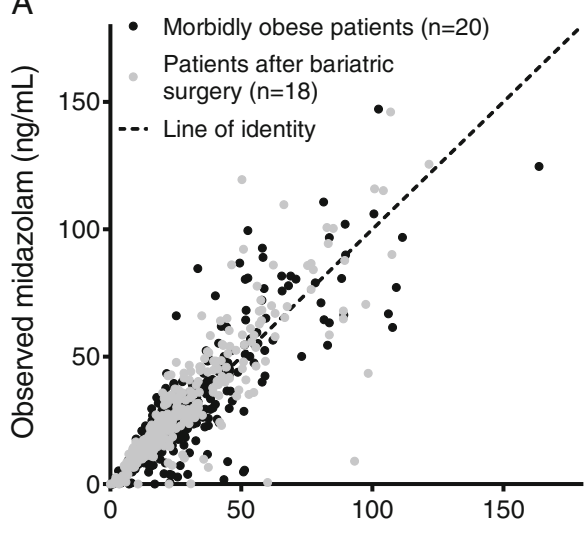

Individual predicted midazolam $(\mathrm{ng} / \mathrm{mL})$

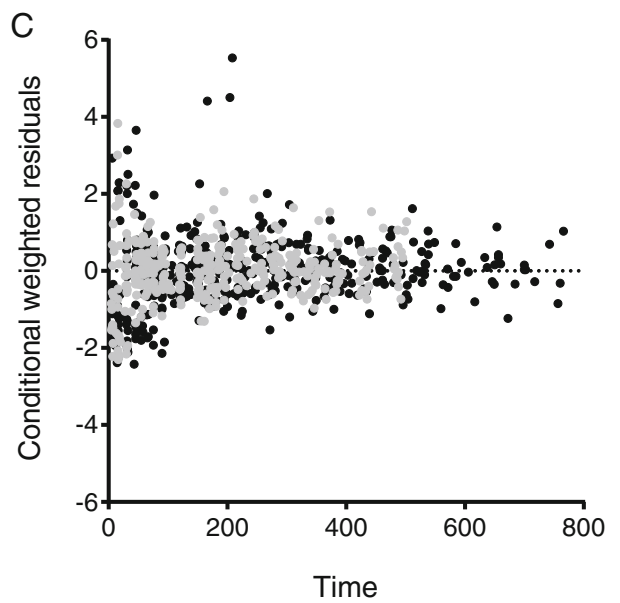

B

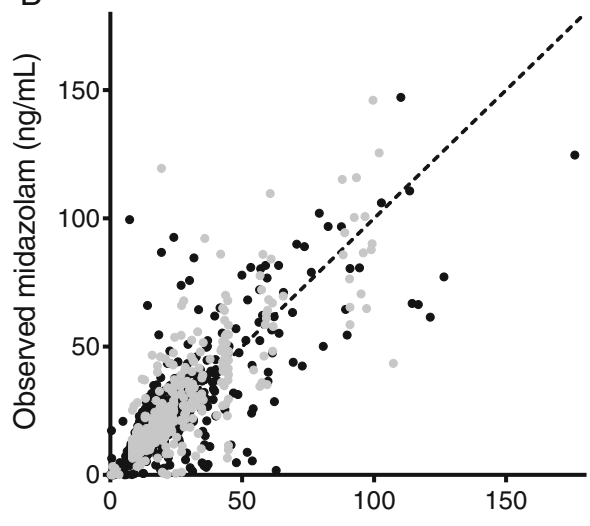

Population predicted midazolam (ng/ml)

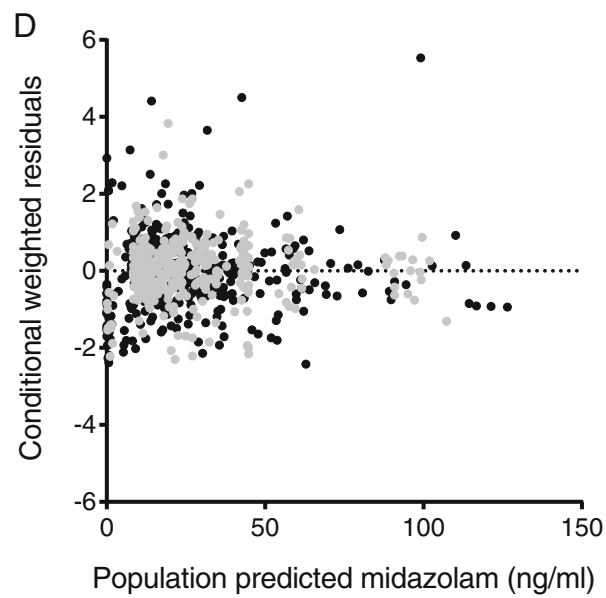




\section{A 5 mg intravenous dose}

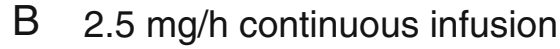

$7.5 \mathrm{mg}$ oral dose
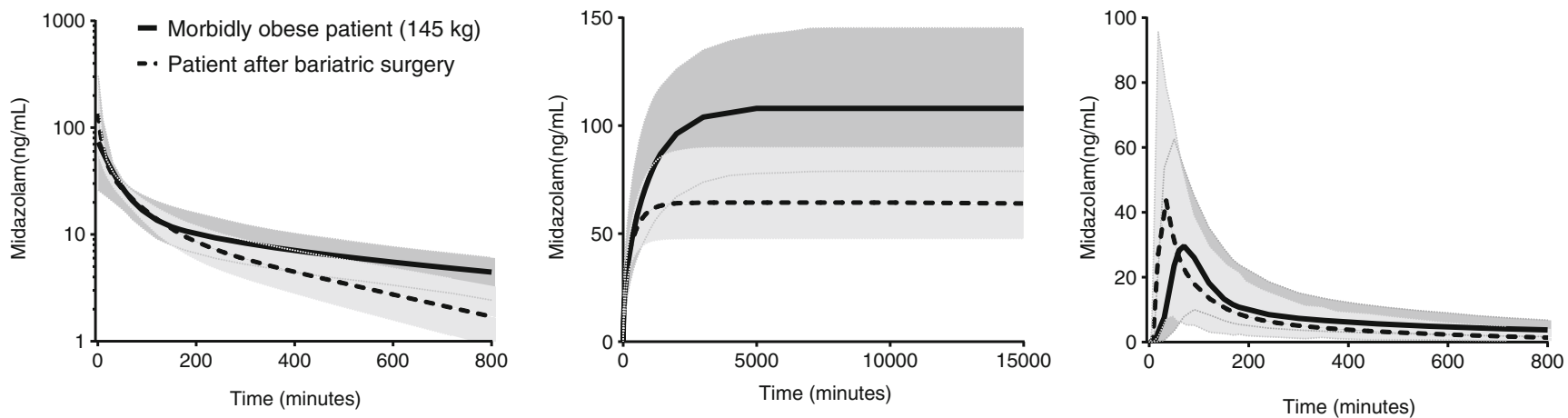

Fig. 3 Population mean (black line) and 90\% interval (grey area) of midazolam concentrations versus time after a $5 \mathrm{mg}$ intravenous dose (a), a $2.5 \mathrm{mg} / \mathrm{h}$ continuous infusion (b) and a $7.5 \mathrm{mg}$ oral dose (c) in morbidly obese patients before bariatric surgery (black solid line) and after bariatric surgery (black dotted line).

midazolam systemic clearance and mean oral transit time were substantially increased while oral bioavailability remained unchanged. Central and peripheral volumes of distribution were generally lower in patients after bariatric surgery. The main finding of this study is the substantial increase in midazolam systemic clearance in all 18 patients 1 year after bariatric surgery compared to their values before surgery. This increase in clearance after bariatric surgery could not be contributed to the decrease in body weight as the body weight model was inferior to the bariatric surgery model $(p<0.05)$. (Fig. 4). Hepatic CYP3A protein expression in liver biopsies has been reported to be unaltered after bariatric surgery indicating unchanged CYP3A mediated clearance (32). However, Tandra et al. also found increased systemic clearance of midazolam in 18 bariatric patients $>1$ year post RYGB surgery in comparison with 18 controls $(1.57 \pm 0.95$ versus $0.92 \pm 0.72 \mathrm{~L} / \mathrm{min}, p=0.03$ ) (33). In their study, control patients were matched for age, sex, race, and body mass index, while in our study we compared midazolam pharmacokinetics within the same cohort using a follow up design. Comparing our values to systemic clearance values in healthy volunteers (Fig. 4a), it seems that systemic clearance values post bariatric surgery are higher than those of healthy volunteers found in the literature $(25,34-40)$. We anticipate that the increase in systemic midazolam clearance may be explained by a recovery of hepatic CYP3A activity due to decreased inflammation status, as many studies have shown a reduction in inflammatory adipokines in the plasma of patients after bariatric surgery (22). Moreover, it has been shown in in vitro and animal studies that a fatty liver, which is highly associated with morbid obesity, represses CYP3A activity $(41,42)$. While CYP3A activity may have recovered 1 year after bariatric surgery, Immonen et al. showed on the other hand that 6 months after bariatric surgery both the fat content and size of the liver is reduced to almost the level of lean subjects, which could imply a reduced clearance (21). The fact that we identify in our study an increase in systemic midazolam clearance post bariatric surgery implies that the increased CYP3A activity per unit of liver compensates and surpasses the reduction in liver size that is associated with bariatric surgery in these patients. Another explanation could be a recovery in total liver blood flow, due to recovery of fatty liver and/
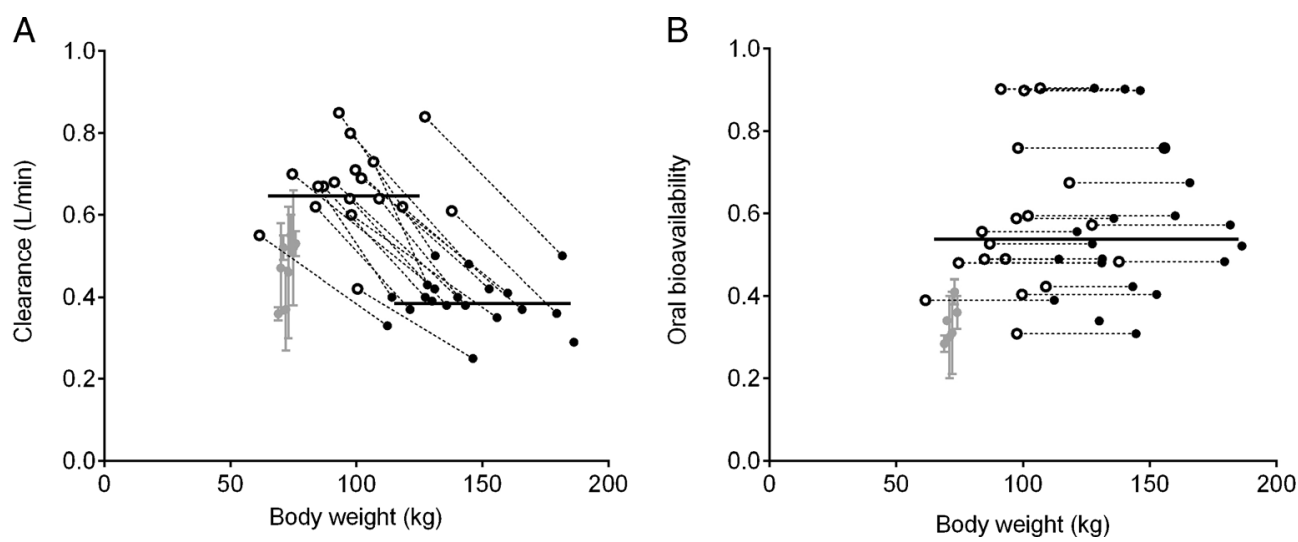

Fig. 4 Empirical bayes estimates (black dots) and population mean estimates (black lines) of midazolam clearance (a) and oral bioavailability (b) of the final pharmacokinetic model in 20 morbidly obese patients (black closed dots) and 18 bariatric patients (black open dots) versus body weight (kg). Parameter values found for healthy volunteers studies from the literature were added for comparison (grey dots) (25,34-40). 
or steatosis (43), but as midazolam is an intermediate extraction ratio drug this seems unlikely (44).

Midazolam mean oral transit time was twice as fast in patients 1 year post bariatric surgery in comparison to before surgery. Decreased $\mathrm{T}_{\max }$ in bariatric surgery patients has been reported before for oral caffeine, tolbutamide, midazolam, omeprazole and duloxetine administration $(33,45)$. The faster midazolam oral absorption may be explained by faster gastric emptying of the stomach due to the reduced stomach size $(12,13,46,47)$. In contrast to more rapid oral absorption, for oral bioavailability, we found no difference before and after bariatric surgery. From a comparison to healthy volunteers (Fig. 4b), it can be concluded that oral bioavailability values in bariatric patients do not seem to return to values found for healthy volunteers, but remain at the level of those found for morbidly obese patients. The oral bioavailability value (F) may be deduced to its individual contributors, which are the fraction absorbed $\left(\mathrm{f}_{\mathrm{a}}\right)$, the fraction escaping gut wall metabolism $\left(\mathrm{F}_{\mathrm{G}}\right)$ and the fraction escaping first pass hepatic metabolism $\left(\mathrm{F}_{\mathrm{H}}\right)$.

As midazolam is a highly soluble and permeable drug, $\mathrm{f}_{\mathrm{a}}$ can be assumed to be equal to 1 in morbidly obese patients before and after surgery (48). In addition, assuming no change in hepatic blood flow and blood to plasma partition ratio before and after surgery, $\mathrm{F}_{\mathrm{H}}$ will decrease approximately 1.68 times post bariatric surgery as a result of 1.68 times increased systemic clearance. So, given the unchanged total bioavailability, $\mathrm{F}_{\text {total, }}$ we identified in our study, this implies that the midazolam fraction escaping gut wall $\left(\mathrm{F}_{\mathrm{G}}\right)$ increases 1.68 times 1 year after bariatric surgery. An increase in $\mathrm{F}_{\mathrm{G}}$ was also predicted by Darwich et al., who showed that post RYGB surgery the $\mathrm{F}_{\mathrm{G}}$ of CYP3A substrate simvastatin increased with $13 \%$ (49). Increased $\mathrm{F}_{\mathrm{G}}$ may be due to the bypass of the intestines resulting from this type of surgery, in which normally approximately $75 \%$ of the midazolam dose would have been absorbed $(48,50)$. Another explanation could be an increase in splanchnic blood flow resulting in an increase in $\mathrm{F}_{\mathrm{G}}$, however this seems very unlikely in view of the decrease in bodyweight associated with bariatric surgery and therefore an anticipated decrease in splanchnic blood flow instead of increase.

For midazolam central and peripheral volume of distribution we observed overall lower values in post bariatric surgery patients without variation due to body weight $(p>0.05$, Table II). While we anticipate that this is due to the smaller range in bodyweight in the bariatric patient group, as within the morbidly obese patient group volume of distribution was highly depended on body weight as was reported before (25). To account for the influence of body weight on both the first and second peripheral volume of distribution, the second peripheral volume was modeled as a fraction of the first volume of distribution. The general reduction in volume of distribution after bariatric surgery may result from weight loss resulting in substantial reductions in blood volume and adipose tissue (51).
Although this study provides unique information on the pharmacokinetics of midazolam after both oral and intravenous dose administration in a new and emerging patient population, the study may have some limitations. First, 2 of the 18 patients underwent a sleeve gastrectomy procedure, which is an insufficient number to draw any conclusion on the effect of a sleeve gastrectomy on midazolam pharmacokinetics. However, these 2 patients did show a major loss in body weight to an extent that was similar to that of the 16 gastric bypass patients, which was the reason why we included these patients in the analysis. Moreover, when excluding these two patients from the dataset, none of parameter estimates were significantly different (data not shown). Second, at occasion 1, patients underwent surgery and anesthesia, which was not the case during occasion 2. This may potentially have influenced the results on midazolam PK we report in this study. It is well known that during a surgery cardiac output is lowered which may have caused lower midazolam clearances for morbidly obese patients. However, the duration of surgery and anesthesia was quite limited $(86.4 \pm 31 \mathrm{~min})$ in comparison to the study period of the first occasion ( $\sim 660 \mathrm{~min})$, minimizing the influence of surgery. Moreover, bariatric surgery was performed using minimally invasive techniques (laparoscopic techniques) reducing hemodynamically induced changes. Furthermore, surgery was performed $159 \pm 67$ min after oral midazolam dose administration, which excludes any influence of surgery/anesthesia on midazolam the oral absorption phase. For these reasons, we think that the short duration of surgery/anesthesia during the first occasion is not of significant influence on the conclusion drawn based on these data.

The midazolam dose simulations provide insight in how the altered pharmacokinetics in bariatric patients affect midazolam concentration time profiles after oral or intravenous administration. A $5 \mathrm{mg}$ intravenous midazolam bolus dose results in higher initial midazolam concentrations in a patient post bariatric surgery than in a morbidly obese patient. This indicates that, in comparison to morbidly obese patients, a lower intravenous bolus dose may be anticipated in patients post bariatric surgery, as after a intravenous bolus dose, midazolam effect is primarily determined by the initial concentrations. For an continuous intravenous infusion, a lower steady state concentration is reached in a bariatric patient due to the almost doubled midazolam clearance value compared to morbidly obese patients. So to reach a similar steady state concentration in a bariatric patient a higher $\mathrm{mg} / \mathrm{h}$ dose seems necessary. In this respect, it is important to realise that a postbariatric surgery patient does not only need a higher dose than before surgery but also may need a higher dose in $\mathrm{mg} / \mathrm{h}$ than a non-obese patient given the differences in clearance values (Fig. 4). Furthermore, the steady state concentration is reached 2.5 times faster in a bariatric surgery patient compared to a morbidly obese patient. Finally, a midazolam oral 
tablet will result in increased $\mathrm{C}_{\max }$ and earlier $\mathrm{T}_{\max }$ in a bariatric patient.

Finally, the influence of bariatric surgery on midazolam systemic clearance found in this study may be extrapolated to other drugs which are also primarily metabolised by CYP3A, as midazolam is considered a CYP3A probe substrate (23). While the extrapolation potential depends on many factors, including extraction ratio and physicochemical properties of the drug, it may be speculated that other major CYP3A substrates may show a similar effect of bariatric surgery on systemic clearance.

\section{CONCLUSION}

In conclusion, in this cohort study in morbidly obese patients, systemic clearance was 1.7 times higher 1 year after bariatric surgery, which may potentially result from an increase in hepatic CYP3A activity per unit of liver. Even though mean oral transit time was found to be faster, oral bioavailability remained unchanged, which considering the increased systemic clearance implies an increase in the midazolam fraction escaping intestinal first pass metabolism after an oral administration. In patients after a bariatric surgery, these alterations will result in lower midazolam steady state concentrations and in higher and earlier peak concentrations after oral administration in comparison to morbidly obese patients before bariatric surgery.

\section{ACKNOWLEDGMENTS AND DISCLOSURES}

The bariatric nurses Brigitte Bliemer and Silvia Samsom (St. Antonius Hospital, Nieuwegein, The Netherlands) are acknowledged for their help in recruiting patients, the recovery department and personnel under supervision of Marion Brem (St. Antonius Hospital, Nieuwegein, The Netherlands) for their hospitality and help during the second study visit and patients for participating in this study both before and 1 year after bariatric surgery.

This study was sponsored by ZonMW (The Netherlands Organisation for Health Research and Development), project number: 836011008. The authors declare no conflicts of interest.

Open Access This article is distributed under the terms of the Creative Commons Attribution 4.0 International License (http://creativecommons.org/licenses/by/4.0/), which permits unrestricted use, distribution, and reproduction in any medium, provided you give appropriate credit to the original author(s) and the source, provide a link to the Creative Commons license, and indicate if changes were made.

\section{REFERENCES}

1. Shields M, Garroll MD, Ogden CL. Adult obesity prevalence in Canada and the United States. In: Services usdohah, editor. Hyattsville, MD: NCHS Data Brief; 2011.

2. IASO. International Association for the Study of Obesity. In: IASO.

3. Hautvast J. Overgewicht en obesitas. In: Health Council of the Netherlands; 2003.

4. Craig RMJ, et al. Cardiovascular disease and risk factors in adults. London: The Information Centre for Health and Social Care. In: Health Survey for England 2006; 2008.

5. Andreyeva T, Michaud PC, van Soest A. Obesity and health in Europeans aged 50 years and older. Public Health. 2007;121(7): 497-509.

6. Buchwald H, Avidor Y, Braunwald E, Jensen MD, Pories W, Fahrbach K, et al. Bariatric surgery: a systematic review and meta-analysis. JAMA. 2004;292(14):1724-37.

7. Sjostrom L, Lindroos AK, Peltonen M, Torgerson J, Bouchard C, Carlsson B, et al. Lifestyle, diabetes, and cardiovascular risk factors 10 years after bariatric surgery. N Engl J Med. 2004;351(26):268393.

8. Buchwald H, Oien DM. Metabolic/bariatric surgery worldwide 2011. Obes Surg. 2013;23(4):427-36.

9. Edwards A, Ensom MH. Pharmacokinetic effects of bariatric surgery. Ann Pharmacother. 2012;46(1):130-6.

10. Kral JG, Naslund E. Surgical treatment of obesity. Nat Clin Pract Endocrinol Metab. 2007;3(8):574-83.

11. Baltasar A, Serra C, Perez N, Bou R, Bengochea M, Ferri L. Laparoscopic sleeve gastrectomy: a multi-purpose bariatric operation. Obes Surg. 2005;15(8):1124-8.

12. Horner KM, Byrne NM, Cleghorn GJ, Naslund E, King NA. The effects of weight loss strategies on gastric emptying and appetite control. Obes Rev. 2011;12(11):935-51.

13. Melissas J, Leventi A, Klinaki I, Perisinakis K, Koukouraki S, de Bree E, et al. Alterations of global gastrointestinal motility after sleeve gastrectomy: a prospective study. Ann Surg. 2013;258(6): 976-82.

14. Zanger UM, Schwab M. Cytochrome P450 enzymes in drug metabolism: regulation of gene expression, enzyme activities, and impact of genetic variation. Pharmacol Ther. 2013;138(1):103-41.

15. Renton KW. Regulation of drug metabolism and disposition during inflammation and infection. Expert Opin Drug Metab Toxicol. 2005; 1(4):629-40.

16. Wellen KE, Hotamisligil GS. Inflammation, stress, and diabetes. J Clin Invest. 2005;115(5):1111-9.

17. Fantuzzi G. Adipose tissue, adipokines, and inflammation. J Allergy Clin Immunol. 2005;115(5):911-9. quiz 920.

18. Mathieu P, Lemieux I, Despres JP. Obesity, inflammation, and cardiovascular risk. Clin Pharmacol Ther. 2010;87(4):407-16.

19. Aitken AE, Richardson TA, Morgan ET. Regulation of drugmetabolizing enzymes and transporters in inflammation. Annu Rev Pharmacol Toxicol. 2006;46:123-49.

20. Yang J, Hao C, Yang D, Shi D, Song X, Luan X, et al. Pregnane X receptor is required for interleukin-6-mediated down-regulation of cytochrome P450 3A4 in human hepatocytes. Toxicol Lett. 2010;197(3):219-26.

21. Immonen $\mathrm{H}$, Hannukainen JC, Iozzo $\mathrm{P}$, Soinio $\mathrm{M}$, Salminen $\mathrm{P}$, Saunavaara $\mathrm{V}$, et al. Effect of bariatric surgery on liver glucose metabolism in morbidly obese diabetic and non-diabetic patients. J Hepatol. 2014;60(2):377-83.

22. Rao SR. Inflammatory markers and bariatric surgery: a meta-analysis. Inflamm Res. 2012;61(8):789-807. 
23. Streetman DS, Bertino Jr JS, Nafziger AN. Phenotyping of drugmetabolizing enzymes in adults: a review of in-vivo cytochrome P450 phenotyping probes. Pharmacogenetics. 2000;10(3):187-216.

24. Flockhart A. Cytochrome P450 drug interaction table. Available from: http://www.greenbridgemed.com/wp-content/uploads/ 2011/09/Drugs-using-P450-Hepatic-metabolism.pdf.

25. Brill MJ, van Rongen A, Houwink AP, Burggraaf J, van Ramshorst $\mathrm{B}$, Wiezer RJ, et al. Midazolam pharmacokinetics in morbidly obese patients following semi-simultaneous oral and intravenous administration: a comparison with healthy volunteers. Clin Pharmacokinet. 2014;53(10):931-41.

26. Sjostrom L, Narbro K, Sjostrom CD, Karason K, Larsson B, Wedel $\mathrm{H}$, et al. Effects of bariatric surgery on mortality in Swedish obese subjects. N Engl J Med. 2007;357(8):741-52.

27. Sessler CN, Gosnell MS, Grap MJ, Brophy GM, O’Neal PV, Keane KA, et al. The Richmond Agitation-Sedation Scale: validity and reliability in adult intensive care unit patients. Am J Respir Crit Care Med. 2002;166(10):1338-44.

28. Beal S, Sheiner LB, Boeckmann A, Bauer RJ. NONMEM User's Guides. (1988-2011) Ellicott City, MD, USA; 2011.

29. Brendel K, Comets E, Laffont CM, Laveille C, Mentré F. Metrics for external model evaluation with an application to the population pharmacokinetics of gliclazide. Pharm Res. 2006;23:2036-49.

30. Savic RM, Jonker DM, Kerbusch T, Karlsson MO. Implementation of a transit compartment model for describing drug absorption in pharmacokinetic studies. J Pharmacokinet Pharmacodyn. 2007;34(5):711-26.

31. Janmahasatian S, Duffull SB, Ash S, Ward LC, Byrne NM, Green B. Quantification of lean bodyweight. Clin Pharmacokinet. 2005;44(10):1051-65.

32. Bell LN, Temm CJ, Saxena R, Vuppalanchi R, Schauer P, Rabinovitz $\mathrm{M}$, et al. Bariatric surgery-induced weight loss reduces hepatic lipid peroxidation levels and affects hepatic cytochrome P450 protein content. Ann Surg. 2010;251(6):1041-8.

33. Tandra S, Chalasani N, Jones DR, Mattar S, Hall SD, Vuppalanchi R. Pharmacokinetic and pharmacodynamic alterations in the Roux-en-Y gastric bypass recipients. Ann Surg. 2013;258(2):262-9.

34. Greenblatt DJ, Abernethy DR, Locniskar A, Harmatz JS, Limjuco RA, Shader RI. Effect of age, gender, and obesity on midazolam kinetics. Anesthesiology. 1984;61(1):27-35.

35. Thummel KE, O'Shea D, Paine MF, Shen DD, Kunze KL, Perkins JD, et al. Oral first-pass elimination of midazolam involves both gastrointestinal and hepatic CYP3A-mediated metabolism. Clin Pharmacol Ther. 1996;59(5):491-502.

36. Gorski JC, Hall SD, Jones DR, VandenBranden M, Wrighton SA. Regioselective biotransformation of midazolam by members of the human cytochrome P450 3A (CYP3A) subfamily. Biochem Pharmacol. 1994;47(9):1643-53.

37. Lee JI, Chaves-Gnecco D, Amico JA, Kroboth PD, Wilson JW, Frye RF. Application of semisimultaneous midazolam administration for hepatic and intestinal cytochrome P450 3A phenotyping. Clin Pharmacol Ther. 2002;72(6):718-28.
38. Shord SS, Chan LN, Camp JR, Vasquez EM, Jeong HY, Molokie $\mathrm{RE}$, et al. Effects of oral clotrimazole troches on the pharmacokinetics of oral and intravenous midazolam. Br J Clin Pharmacol. 2010;69(2):160-6.

39. Mandema JW, Tuk B, van Steveninck AL, Breimer DD, Cohen AF, Danhof M. Pharmacokinetic-pharmacodynamic modeling of the central nervous system effects of midazolam and its main metabolite alpha-hydroxymidazolam in healthy volunteers. Clin Pharmacol Ther. 1992;51(6):715-28.

40. van Gerven JM, Roncari G, Schoemaker RC, Massarella J, Keesmaat $\mathrm{P}$, Kooyman $\mathrm{H}$, et al. Integrated pharmacokinetics and pharmacodynamics of Ro 48-8684, a new benzodiazepine, in comparison with midazolam during first administration to healthy male subjects. Br J Clin Pharmacol. 1997;44(5):487-93.

41. Ghose R, Omoluabi O, Gandhi A, Shah P, Strohacker K, Carpenter KC, et al. Role of high-fat diet in regulation of gene expression of drug metabolizing enzymes and transporters. Life Sci. 2011;89(1-2):57-64.

42. Buechler C, Weiss TS. Does hepatic steatosis affect drug metabolizing enzymes in the liver? Curr Drug Metab. 2011;12(1):24-34.

43. Farrell GC, Teoh NC, McCuskey RS. Hepatic microcirculation in fatty liver disease. Anat Rec (Hoboken). 2008;291(6):684-92.

44. Tsunoda SM, Velez RL, von Moltke LL, Greenblatt DJ. Differentiation of intestinal and hepatic cytochrome P450 3A activity with use of midazolam as an in vivo probe: effect of ketoconazole. Clin Pharmacol Ther. 1999;66(5):461-71.

45. Roerig JL, Steffen KJ, Zimmerman C, Mitchell JE, Crosby RD, Cao L. A comparison of duloxetine plasma levels in postbariatric surgery patients versus matched nonsurgical control subjects. J Clin Psychopharmacol. 2013;33(4):479-84.

46. Ardila-Hani A, Soffer EE. Review article: the impact of bariatric surgery on gastrointestinal motility. Aliment Pharmacol Ther. 2011;34(8):825-31.

47. Braghetto I, Davanzo C, Korn O, Csendes A, Valladares H, Herrera E, et al. Scintigraphic evaluation of gastric emptying in obese patients submitted to sleeve gastrectomy compared to normal subjects. Obes Surg. 2009;19(11):1515-21.

48. Jamei M, Turner D, Yang J, Neuhoff S, Polak S, RostamiHodjegan A, et al. Population-based mechanistic prediction of oral drug absorption. AAPS J. 2009;11(2):225-37.

49. Darwich AS, Pade D, Ammori BJ, Jamei M, Ashcroft DM, Rostami-Hodjegan A. A mechanistic pharmacokinetic model to assess modified oral drug bioavailability post bariatric surgery in morbidly obese patients: interplay between CYP3A gut wall metabolism, permeability and dissolution. J Pharm Pharmacol. 2012;64(7):1008-24.

50. Paine MF, Khalighi M, Fisher JM, Shen DD, Kunze KL, Marsh CL, et al. Characterization of interintestinal and intraintestinal variations in human CYP3A-dependent metabolism. J Pharmacol Exp Ther. 1997;283(3):1552-62.

51. Busetto L, Tregnaghi A, De Marchi F, Segato G, Foletto M, Sergi $\mathrm{G}$, et al. Liver volume and visceral obesity in women with hepatic steatosis undergoing gastric banding. Obes Res. 2002;10(5):40811 . 